\title{
PERANAN ABBOT SEBAGAI REPRESENTASI KRISTUS DAN IMPLIKASINYA DALAM PENDIDIKAN ANAK USIA DINI
}

\author{
Meiliana Evita Benes \\ STT Amanat Agung \\ meiliana01evita@gmail.com
}

\begin{abstract}
The presence of the spiritual leaders who have the absolute power is aptly directly related to the spiritual growth of the people whom they served. Abbots in monastic times are examples of leaders with high qualifications to perform instructional tasks related to spiritual formation. The development in history shows the change and complexity of this role. Abbots' role is important not only for the adults, but also for the children-even to the early childhood. Because spiritual leaders are present as representatives of Christ to show true, authentic, whole, and balanced love. Christ is the primary authority in this instructional process. Early childhood also needs the presence of authorities to support their spiritual formation. To achieve this goal, it is important to consider the role of spiritual leaders and spiritual needs based on early childhood development.
\end{abstract}

Keywords: representation of Christ, spirituality, early childhood, abbot, authority

\begin{abstract}
Abstrak
Kehadiran pemimpin rohani yang memiliki kekuasaan mutlak jelas berkaitan langsung dengan pertumbuhan spiritual orang-orang yang dilayani. Abbot (kepala biara) di masa biara adalah contoh pemimpin dengan kualifikasi yang tinggi untuk melakukan tugas instruksional terkait dengan formasi spiritual. Perkembangan sejarah kemudian menunjukkan perubahan dan kompleksitas peran ini. Peranan abbot tidak hanya penting bagi orang dewasa, tetapi juga anak-anak-bahkan anak usia dini. Sebab, pemimpin rohani hadir sebagai representasi Kristus untuk menunjukkan kasih yang benar, otentik, utuh dan seimbang. Kristus adalah otoritas utama dalam proses instruksional ini. Anak usia dini juga membutuhkan kehadiran pihak berotoritas untuk mendukung formasi spiritualitas mereka. Untuk mencapai tujuan ini, maka hal yang penting untuk
\end{abstract}


diperhatikan adalah melihat peranan pemimpin rohani dan kebutuhan spiritual berdasarkan perkembangan anak usia dini.

Kata-kata Kunci: representasi Kristus, spiritualitas, anak usia dini, abbot (kepala biara), otoritas

\section{Pendahuluan}

Ada berbagai pengertian mengenai makna spiritualitas atau kerohanian. Penelitian ini didasarkan pada kerangka bahwa spiritualitas merupakan hasil pembaruan yang terus-menerus dikerjakan oleh Roh Kudus dalam diri seseorang yang telah menerima Kristus sebagaimana yang menjadi penekanan Rasul Paulus. ${ }^{1}$ Spiritualitas tidak dibatasi hanya kepada hal-hal luar biasa yang hanya berada di alam roh dan menolak hal-hal material, melainkan melingkupi berbagai aspek secara holistik. Kehidupan yang diberdayakan oleh Roh Kudus memberi kesempatan bagi seseorang untuk bertindak dengan pantas dalam keseluruhan hidup. ${ }^{2}$ Spiritualitas yang utuh akan terlihat dengan lebih jelas di dalam interaksi kehidupan sehari-hari.

Terkait dengan perkembangan spiritualitas, masa biara di Abad Pertengahan mendapatkan sorotan yang kuat terkait dengan dorongan manusia untuk mencapai hidup spiritual yang penuh. Robin Maas, seorang pegiat dalam dunia pendidikan Kristen, menjelaskan dengan ringkas dan padat mengenai landasan teologis sebuah biara. Ia menjelaskan bahwa, ${ }^{3}$

Just as Christ was driven into the wilderness by the Holy Spirit for a time of testing and tutelage, so the first monks and nuns were compelled by the power of the Word of God to "leave the world" and begin the search for God in the desert regions of Egypt and Palestine. Whether geographically located in the actual desert or withdrawn into the monastic enclosure, these men and women were less concerned to reject the world and flee from it (fuga mundi) than they were to imitate Christ (imitation Christi) in his perfect submission to the Father's will. They hungered for communion with God and peace with one another. Theirs, however, was no moderate hunger. Famished with the desire to love God and neighbor perfectly, the first generations of monks and nuns pushed

${ }^{1}$ Rm. 8:5-6, 13-15 (TB-LAI).

${ }^{2}$ Arthur Holder, The Blackwell Companion to Christian Spirituality (Malden, MA: Blackwell, 2005).

${ }^{3}$ Robin Maas, Spiritual Traditions for the Contemporary Church (Nashville, TN: Abingdon, 1990), 56. 
249 Peranan Abbot Sebagai Representasi Kristus dan Implikasinya dalam Pendidikan Anak Usia Dini

themselves to the limits of their physical and psychological endurance in this great experiment in gospel living.

Model biara adalah salah satu cara untuk mencapai kasih sebagai bagian implementasi yang tertinggi dan terutama umat manusia-mengasihi Allah dan sesama-yang dilakukan melalui penerapan rule atau aturan-aturan yang secara sengaja dibuat dan dipatuhi bersama-sama. ${ }^{4}$ Melalui persekutuan (koinonia), setiap biarawan atau biarawati dapat mempraktikkan dan merasakan kasih. Setiap kegiatan yang dilakukan untuk mencapai tujuan penerapan kasih dilakukan di bawah bimbingan abbot (kepala biara).

Peranan kepala biara secara esensial tidak banyak mengalami perubahan, tetapi konteks zaman memiliki banyak pengaruh terhadap peran tersebut. Melalui penelusuran ini, diharapkan bahwa peran dan fungsi seorang kepala biara di tengah komunitas biara bisa dipahami dengan lebih baik. Tulisan ini hanya menyusuri beberapa masa yang dinilai oleh penulis dapat memperlihatkan berbagai keunikan pemikiran dan pemahaman teologis yang melatarbelakangi perkembangan peranan kepala biara, kemudian melihat kaitannya dengan spiritualitas anak usia dini.

Sebuah penelitian yang dilakukan oleh Donald Ratcliff (2007) menunjukkan bahwa penelitian mengenai spiritualitas anak-terkhusus di dunia bagian Barat-baru kembali mendapatkan perhatian signifikan di dalam dunia penelitian hanya dalam kurun satu abad terakhir saja. ${ }^{5}$ Itu berarti, perkembangan spiritualitas anak cenderung diabaikan dan itu menandai bahwa ada banyak aspek yang tidak diperhatikan dalam pendidikan bagi anakanak, terkhusus anak-anak dalam usia yang lebih muda. Padahal, dalam penelitian yang dilakukan oleh David Hay, spiritualitas anak usia dini perlu diperhatikan oleh seluruh kalangan-bukan saja hanya oleh guru agama - karena hal ini akan memengaruhi tumbuh kembang anak secara menyeluruh. ${ }^{6}$ Kegagalan memperhatikan spiritualitas anak usia dini akan mengakibatkan banyak kegagalan di masa pra-remaja dan terus berlanjut hingga anak secara penuh berada di tengah masyarakat. Beberapa hal yang kemudian menjadi sorotan adalah toleransi yang besar pada ketidakadilan sosial, kecenderungan untuk menjadi individualis dan konsumeris, bahkan menjadi pelaku kriminal. ${ }^{7}$

${ }^{4}$ Ibid., 61.

5 Donald Ratcliff, "'The Spirit of Children Past': A Century of Children's Spirituality Research," Christian Education Journal: Research on Educational Ministry, Vol. 4, No. 2 (2007): 218, https://doi.org/10.1177/073989130700400203.

${ }^{6}$ David Hay, "Why Should We Care about Children's Spirituality?" Pastoral Care in Education, Vol. 16, No. 1 (1998): 15, https://doi.org/10.1111/1468-0122.00078.

${ }^{7}$ Ibid., 13. 
Berdasarkan pemikiran dan isu yang berkembang, maka sangat penting untuk mengembalikan perhatian kepada formasi spiritual anak. Pertanyaannya adalah di mana peran orang dewasa dalam kaitannya dengan formasi spiritual anak usia dini? Apa saja yang menjadi kebutuhan anak usia dini dan bagaimana orang dewasa melakukan peran sebagai pihak otoritatif ini? Penelitian ini diharapkan dapat menjadi bagian berkelanjutan untuk memberi perhatian khusus pada formasi spiritual anak usia dini melalui peranan otoritas yang penuh dengan kasih Kristus dalam masa tumbuh kembang mereka. Artikel ini memperlihatkan bahwa peranan abbot dapat menjadi model peranan orang dewasa dalam menumbuhkembangkan formasi spiritual anak usia dini.

Menggunakan metode penelitian historis, tulisan ini berusaha untuk memberi pemahaman yang mendalam terkait dengan peranan abbot di dalam sepanjang Abad Pertengahan. Model metode penelitian historis yang secara khusus digunakan dalam penelitian ini adalah metode integral. Dalam buku Church History: An Introduction to Research, Reference Works, and Methods, yang ditulis oleh Bradley dan Muller, metode terbaik yang dinilai tepat untuk meneliti sejarah adalah dengan metode integral. Tujuan penggunaan metode ini adalah untuk memahami secara sinkronik perkembangan ide dalam kekristenan yang sudah berlangsung puluhan abad ini. ${ }^{8}$ Proses yang dilakukan meliputi pengumpulan materi, kemudian melakukan proses klasifikasi berdasarkan urutan waktu, lalu melakukan interaksi gagasan makna dari setiap masa. Hasil akhir yang diharapkan adalah pemahaman yang kompleks mengenai isu tertentu dan memiliki kontribusi bagi perkembangan gagasan yang dimaksud.

Untuk melihat perkembangan variabel kedua dalam penelitian ini, yakni pendidikan anak usia dini, hal yang dilakukan adalah dengan melakukan kajian literatur. Cara yang dilakukan adalah melalui pemaparan berbagai literatur untuk melihat perkembangan pendidikan anak usia dini. Beberapa hal yang perlu dikemukakan adalah definisi mengenai anak usia dini, perkembangan dan kebutuhan anak usia dini, serta cara membangun formasi spiritual pada anak usia dini. Tahap berikutnya adalah memaparkan korelasi antara variabel kepala biara dan pendidikan anak usia dini.

Artikel ini dimulai dengan pembahasan peranan kepala biara dalam kehidupan spiritual anak usia dini. Meskipun model pendidikan biara tidak lagi banyak bertahan, namun warisan spiritual ini perlu mendapat perhatian, terkhusus bagi pribadi yang memiliki ketertarikan pada hidup spiritual. Penelusuran melalui sejarah akan memperlihatkan peranan kepala biara seiring dengan

8 James E. Bradley et al., Church History: An Introduction to Research, Reference Works, and Methods, 2 ${ }^{\text {nd }}$ ed. (Grand Rapids, MI: Eerdmans, 1995), 31. 

Implikasinya dalam Pendidikan Anak Usia Dini

perkembangan dan perubahan zaman. Kemudian, melihat kaitan peran ini secara khusus dengan penerapan kasih sebagai landasan hidup pribadi yang berotoritas. Bagian terakhir dalam pemaparan ini berusaha untuk memperlihatkan hubungan antara pihak berotoritas dalam pendidikan anak usia dini di dalam landasan kasih.

\section{Kehadiran Abbot (Kepala Biara) dalam Biara}

Ciri khas yang sangat kuat dari kehidupan biara adalah kehadiran abbot (kepala biara). Meskipun sering terlihat sebagai pribadi yang kaku dan tegas, sesungguhnya kepala biara sedang mengerjakan tugas yang amat penting terkait dengan pertumbuhan spiritual orang-orang yang sedang ia layani. Tugas utama dari kepala biara adalah memberi pengawasan kepada para biarawan untuk mencapai pemenuhan hidup spiritual yang matang. Keberhasilan untuk memilih kandidat pemimpin yang baik akan memengaruhi kondisi pertumbuhan dari komunitas tersebut. ${ }^{9}$ Oleh sebab itu, proses pemilihan kepala biara adalah bagian yang sangat penting di dalam kehidupan sebuah komunitas mengingat peran seorang kepala biara adalah hal yang krusial.

Di sepanjang sejarah, peranan kepala biara tidak mengalami perubahan yang signifikan. Tugas utama yang terkait dengan memberi pengawasan dan mendidik berdasarkan teladan hidup tetap menjadi ciri khas dari seorang kepala biara. ${ }^{10}$ Akan tetapi, pemaknaan yang berbeda bermunculan seiring dengan berkembangnya peradaban dan perubahan dalam masyarakat sosial. Beberapa perkembangan dalam sejarah yang terlihat sangat mencolok akan dibahas di dalam bagian ini sebagai upaya untuk melihat dengan lebih seksama makna dan peranan kepala biara dalam komunitas.

\section{Kepala Biara sebagai Bapa}

Pribadi yang mendapat sorotan besar di masa kejayaan biara pada awal Abad Pertengahan adalah St. Benedict atau yang dikenal sebagai St. Benediktus (480-547M). Ia adalah seorang yang dikenal sebagai penulis (tidak secara langsung) dari kumpulan aturan dalam biara_-yang dipimpin langsung olehnya — The Rule of St. Benedict (RB). Bertahan selama belasan abad sejak karya ini dirampungkan oleh St. Gregorius Agung (590-604M), ${ }^{11}$ aturanaturan ini tetap relevan di dalam berbagai komunitas iman dengan

9 Martin Heale, The Abbots and Priors of Late Medieval and Reformation England (Oxford: Oxford University Press, 2016), 54.

${ }^{10}$ Ibid., 57.

11 Carolinne White, The Rule of Benedict (London: Penguin Classics, 2008), $x$. 
berbagai penyesuaian. ${ }^{12}$ Salah satu pribadi yang menjadi aset dan mendapat perhatian besar dari St. Benediktus adalah kepala biara. Beberapa aturan yang dipaparkan dalam kumpulan aturan ini menjelaskan banyak tentang pribadi berotoritas ini.

Kepala biara adalah sebuah panggilan yang berharga dan menuntut pertanggungjawaban yang sangat tinggi. Panggilan ini terkait dengan penjelasan dalam RB 2.1, 2 yang berbunyi, "The abbot who is worthy of ruling a monastery ought always to remember what he is called; he should live up to the name of superior by his actions. He is believed to represent Christ in the monastery, for he is called by his name." ${ }^{\prime 13}$ Kepala biara melayani di tengah biara bukan sebagai dirinya sendiri, melainkan sebagai pribadi yang membawa nama Kristus di tengah biara. Alasan penamaan abbot (bapa) merujuk pada kehadirannya dalam membawa visi Kristus sebagai pihak berotoritas dalam biara.

Will Derkse, seorang filsuf berkebangsaan Belanda, memberikan penekanan bahwa alasan peran fatherbood dari seorang kepala biara adalah karena tugas yang ditanggung amat berat. ${ }^{14}$ Dalam praktiknya, cara yang dilakukan kepala biara kepada para biarawan sebagai proses pendisiplinan dilakukan dengan dua cara, yaitu mengajar secara lisan dan juga mempraktikkan secara langsung (RB 2.12). ${ }^{15}$ Kepala biara mempertanggungjawabkan pertumbuhan spiritual para biarawan langsung kepada Allah ketika

12 Peranan dan fungsi kehadiran RB juga telah menjadi minat riset di kalangan para pemikir kontemporer, dan yang menarik adalah bagaimana mereka mengaitkan itu dalam situasi manusia saat ini. Berkemah (camping) digabungkan dengan RB ternyata dapat menolong umat kristiani kontemporer untuk kembali memaknai formasi spiritual di tengah ritme hidup yang padat di tengah masyarakat. Lihat Craig Miller, "Schools for the Lord's Service: The Rule of St. Benedict for Christian Camping," Christian Education Journal: Research on Educational Ministry, Vol. 11, No. 2 (2014): 300-317, https://doi.org/10.1177/073989131401100206. Di lain pihak, Jerzy Tupikowski melihat penggunaan RB dalam kaitan bagaimana seorang manusia melihat kembali dan menjalani perannya sebagai manusia di dalam penerapan evangelical counsels: kesucian, kesederhanaan, dan ketaatan kepada Allah. Lihat Jerzy Tupikowski, "Anthropology of the Evangelical Counsels in the School of St. Benedict of Nursia," The Person and the Challenges, Vol. 8, No. 2 (2018): 205 219. Penelitian yang lebih baru oleh Melody Escobar merumuskan fungsi RB untuk menemukan makna hidup di dalam kasih bersama dengan ciptaan yang lain, meskipun sedang berada dalam kondisi yang penuh dengan penderitaan. Lihat Melody Escobar, "Horses of Hospitality: A Transformative Pathway to the Christian Praxis of Love," Spiritus A Journal of Christian Spirituality, Vol. 19, No. 2 (2019): 217-231, 10.1353/scs.2019.0028.

13 'Terrence G. Kardong, Benedict's Rule: A Translation and Commentary (Collegeville, MN: The Liturgical Press, 1996), 47.

${ }^{14}$ Wil Derkse, The Rule of Benedict for Beginners: Spirituality for Daily Life (Collegeville, MN: The Liturgical Press, 2003), 48-49.

15 Kardong, Benedict's Rule, 48. 


\section{Peranan Abbot Sebagai Representasi Kristus dan}

Implikasinya dalam Pendidikan Anak Usia Dini

hari penghakiman itu datang, termasuk untuk dirinya sendiri. ${ }^{16}$ Oleh sebab itu, kualitas hidup seorang kepala biara adalah hal yang perlu mendapat perhatian yang sangat besar.

Dengan memahami bahwa kepala biara adalah representasi Kristus, maka nilai utama yang harus nampak dari seorang kepala biara adalah kasih Kristus itu sendiri. Kasih Kristus dicerminkan sebagai bentuk komitmen, sebuah wujud nyata dedikasi seorang pemimpin yang berfokus kepada perubahan hidup dari orang yang dilayani. ${ }^{17}$ Lebih daripada itu, kasih yang dimaksud adalah kasih yang melayani, kasih yang diberikan secara adil kepada semua pihak tanpa melakukan pembedaan. Dalam mengasihi, kepala biara harus mengasihi para biarawan dengan tulus dan tidak merujuk pada preferensi tertentu sebagaimana Kristus mengasihi tanpa pembedaan. Jadi, dapat dilihat bahwa refleksi kasih Kristus adalah alasan utama dari peran disiplin kepala biara yang dicatat dalam RB.

Meskipun memimpin dengan penuh kasih, kepala biara tetap dituntut melakukan proses pendisiplinan dengan menerapkan konsekuensi atas segala perbuatan yang dilakukan oleh para biarawan. RB mencatat tahapan-tahapan hukuman yang diberikan mulai dari proses mengingatkan, memberi hukuman ringan (RB 30), melakukan ekskomunikasi dengan tenggat waktu yang ditentukan (RB 23), bahkan hingga mendapat hukuman yang berat dalam bentuk pukulan (RB 28). Setiap proses penghukuman ada di bawah proses pengawasan kepala biara agar para biarawan memiliki kesempatan untuk merasakan kepedulian kasih dari abbot meski sedang menerima konsekuensi. ${ }^{18}$ Tugas tanggung jawab memberi didikan dengan menggunakan konsekuensi (penghukuman) juga turut diseimbangkan dengan sebuah peringatan bagi sang kepala biara (RB 64.12-15), ${ }^{19}$

12. When he must correct someone, he should act prudently and not overdo it. If he is too vigorous in removing the rust, he may break the vessel. 13. Let him always be wary of his own brittleness and remember not to break the bent reed. 14 . We do not mean he should permit vices to flourish but that he should prune them with prudence and charity. As we said previously, he must use the method best suited to the individual. 15. He should aim more at being loved than feared.

16 Adalbert De Vogue, Reading Saint Benedict: Reflections on the Rule (Collegeville, MN: The Liturgical Press, 1994), 45.

${ }^{17}$ Martin, The Rule of Benedict for Beginners, 48.

18 Timothy Fry, The Rule of St. Benedict in English (Collegeville, MN: The Liturgical Press, 1982), 52.

${ }^{19}$ Kardong, Benedict's Rule, 527. 
Seorang kepala biara di masa awal Abad Pertengahan harus senantiasa berusaha untuk menjaga ketegangan antara seorang ayah yang mendidik dengan disiplin, tetapi juga menyatakan kasih dari Kristus.

\section{Kepala Biara sebagai Ibu}

Catatan dalam Abad Pertengahan Lanjutan (bigh medieval, abad ke-12) mengusung sebuah tema baru yang memiliki ciri khas ketika melihat Allah dalam Kristus dan orang-orang yang berpengaruh dalam kepemimpinan Kristen, termasuk kepala biara. Caroline Walker Bynum, seorang professor emeritus yang banyak melakukan penelitian tentang masa Abad Pertengahan, mencatatkan pemahaman para penulis mengenai sisi feminitas yang banyak berkembang di era tersebut. Tulisan-tulisan seperti yang diungkapkan oleh Anselm of Bec, Aelred of Rievaulx, Bernard Clairvoux, Adam of Perseigne, Guerric of Igny dan beberapa penulis lain mengangkat isu seputar Kristus sebagai ibu, yakni melihat kehadiran para pemimpin dari perspektif yang berbeda. ${ }^{20}$ Hal yang disorot bukanlah pada gender, melainkan pada perbedaan peran yang melekat pada seorang pribadi, terkhusus pihak berotoritas.

Bynum memberi pernyataan tegas bahwa hal utama yang diperhatikan dari pernyataan-pernyataan keibuan dari para penulis itu terletak pada perhatian mereka terkait dengan afeksi dalam otoritas. Jadi, terkait dengan otoritas, pihak yang memegang kekuasaan seharusnya menjaga ritme komunitas dengan menunjukkan sisi afeksi, meskipun harus tetap menjaga kedisiplinan dalam mendidik. ${ }^{21}$ Cara menjaga dan mendidik jiwa dengan penuh kasih akan menolong orang-orang yang menerima didikan untuk memiliki keterikatan yang lebih kuat antar satu dengan yang lain, serta memperkuat relasi dengan Allah. ${ }^{22}$ Pemahaman ini memberi keseimbangan terhadap konsep patristik dari pemegang kekuasaan yang sudah bertindak terlalu kaku dan keras dalam proses pendisiplinan.

Bernard Clairvaux (1090-1153), seorang kepala biara, melandaskan pemahamannya mengenai pemimpin sebagai seorang ibu melalui teks dari kitab Kidung Agung. Mengutip bagian seperti Kidung Agung 1, Clairvaux memberi penekanan pada kehadiran "buah dada" sebagai bagian yang menandakan jenis peranan penting yang seharusnya dimiliki oleh pemimpin. Ada banyak pemimpin yang gagal melihat kehadiran setiap jiwa yang dilayani

${ }^{20}$ Caroline Walker Bynum, "Jesus as Mother and Abbot as Mother: Some Themes in Twelfth-Century Cistercian Writing," Medieval Religion: New Approaches, Vol. 15, No. 1975 (2004): 258.

${ }^{21}$ Ibid., 284.

22 Ibid. 
terkait dengan kebutuhan mereka untuk mendapatkan perhatian penuh kasih guna memperhatikan kemajuan hidup spiritual mereka. ${ }^{23}$ Konsep "kewanitaan" seperti ini menunjukkan sebuah compassion, belas kasih yang harus dimiliki oleh seorang pemimpin, termasuk kepala biara yang memiliki tanggung jawab untuk mendidik.

Melengkapi pemahaman Clairvaux, Guerric of Igny (10701157), yang juga merupakan seorang kepala biara, menambahkan kehadiran rahim-pada seorang wanita—di dalam tulisannya. Pemaparan rahim menunjukkan sisi penjagaan, keamanan, dan persatuan yang diberikan ibu kepada anaknya. ${ }^{24}$ Di dalam menjalankan perannya sebagai pemegang otoritas, kepala biara juga memiliki peran untuk mengupayakan proses pendidikan yang lebih "lembut" kepada setiap biarawan. Kehadiran kepala biara sebagai seorang ibu menunjukkan sebuah perkembangan pemahaman dari abad ke-12 mengenai kelemahlembutan seorang pemimpin demi kepentingan orang-orang di dalam komunitas orang percaya, yaitu komunitas biara.

\section{Kepala Biara sebagai "Maria dan Marta"}

Seorang kepala biara dikenal sebagai pribadi yang selalu hadir dalam hidup para biarawan setempat. Hal ini sesuai dengan konsep yang dibahas dalam RB 2.34, 37-39 mengenai peranan kepala biara sebagai berikut, ${ }^{25}$

34. Let him constantly remain aware of the fact that it is souls he has undertaken to direct and he will have to give an account of them. 37. Let him know that anyone who undertakes the direction of souls should be prepared to render an account. 38. Whatever the number of brothers he has under his care, he can be sure that he will have to account for every one of them on judgment day, and certainly of his own soul as well. 39. He should live in continual fear of the judgment that awaits the shepherd concerning the sheep in his charge. And so, the reckoning he must give for others makes him concerned about his own condition.

Peranan seorang kepala biara nampak dari relasi yang dekat dengan sang biarawan sebagai gembala dan domba. Model relasi ini menuntut agar sang kepala biara selalu hadir dekat dengan para biarawan, baik secara fisik dan juga emosi.

\footnotetext{
23 Ibid., 263.

24 Ibid., 266.

${ }^{25}$ Kardong, Benedict's Rule, 49.
} 
Model ini bertahan lama, tetapi juga mengalami berbagai perubahan dan penyesuaian. Dapat dilihat bahwa pergeseran peran dan tugas dari seorang kepala biara nampak cukup mencolok di masa akhir Abad Pertengahan (abad ke-15). Di masa ini biara telah menempati sebuah posisi yang dikenal secara luas dan memengaruhi banyak pihak, artinya biara memiliki posisi yang penting di tengah masyarakat. Hal ini menyebabkan kehadiran kepala biara tidak hanya untuk kepentingan internal, tetapi juga bagi pihak eksternal. Heale mengutip catatan David Knowles, seorang biarawan Inggris abad 19, bahwa tanggung jawab tambahan bagi seorang kepala biara adalah sebagai representasi komunitas di dalam hubungan dengan pihak eksternal biara. ${ }^{26}$ Biara dengan kapasitas yang cukup besar lebih banyak berhubungan langsung dengan publik, oleh sebab itu peranan kepala biara juga berkaitan dengan kondisi wilayah setempat di mana mereka berada.

Bertindak sebagai "Maria dan Marta," seorang kepala biara harus memperhatikan baik kehidupan spiritual dan juga kehidupan sehari-hari para biarawan yang diatur dalam persoalan administratif. Ungkapan ini disampaikan oleh Abbot John Wheathampstead of St. Albans (1425/6) untuk mengingatkan para kepala biara untuk menjaga keseimbangan kedua hal ini. ${ }^{27}$ Kepala biara memiliki tanggung jawab untuk membantu para biarawan memenuhi kebutuhan material sehari-hari mereka di dalam biara. Oleh sebab itu, kepala biara memiliki akses penuh pada keuangan di dalam biara. Namun, meskipun memiliki akses yang besar terkait dengan keuangan biara, hak pemimpin juga perlu dibatasi agar tidak kehilangan kepekaan sebagai pemimpin rohani di tengah komunitas.

Kondisi yang berjauhan secara fisik dan juga memiliki banyak tugas administratif menyebabkan abbot hadir dalam pribadi yang berbeda, ia seringkali harus mempercayakan tugas internal pada pihak superior lainnya/custodes ordinum. ${ }^{28}$ Meski demikian, ia tetap hadir untuk memberi pengawasan meski dari jarak yang jauh. Bahkan di dalam catatan masa late medieval ini, para kepala biara tetap berusaha untuk memberi teladan dalam kehadiran di tengah kesibukan yang mereka jalani. Thomas Wyse of Stone adalah salah satu contoh abbot yang berusaha hadir pada pertemuan ibadah reguler yang diadakan dalam komunitas biara seperti pada waktu matins, vespers, dan ibadah pada hari Minggu. ${ }^{29}$ Tugas dan peranan yang kompleks dari kepala biara tetap menuntut mereka untuk menjaga keseimbangan antara menjalankan tugas yang bersifat

57.

${ }^{26}$ Heale, The Abbots and Priors of Late Medieval and Reformation England,

27 Ibid., 101.

28 Ibid., 58.

${ }^{29}$ Ibid., 91. 
administratif dan juga instruktif, yakni mengajar melalui teladan bagi para biarawan.

Peranan kepala biara dari masa ke masa mengalami perubahan, tetapi tetap signifikan. Perbedaan yang muncul disebabkan oleh banyak faktor, baik dari internal maupun eksternal. Kepala biara ialah seseorang dengan otoritas penuh di dalam komunitas karena perannya sebagai representasi Kristus. Ia hadir di tengah komunitas sebagai pribadi yang kompleks, baik dari segi kualifikasi kualitas hidup spiritual dan juga tanggung jawab secara sosial-administatif. Hadirnya pihak berotoritas di dalam komunitas menandai harapan bahwa akan ada perubahan signifikan (transformasi) di dalam konteks berkomunitas.

Dalam perkembangan biara, selalu ada kesempatan bagi seluruh kalangan usia untuk bergabung di dalamnya. Artinya, formasi spiritual juga dapat terjadi pada semua kalangan, termasuk bagi anak-anak. Berdasarkan kondisi ini, maka komunitas perlu menaruh perhatian dan upaya terhadap formasi spiritual anak, termasuk anak usia dini. Keunikan setiap tahap perkembangan usia dan juga interaksi dengan pihak berotoritas menjadi hal yang penting untuk diperhatikan. Relasi orang dewasa seperti kepala biara selaku pemegang otoritas juga akan lebih bervariasi kepada tahapan usia tertentu.

\section{Membangun Spiritualitas Anak Usia Dini}

Setiap tahapan usia memiliki model dan tahapan dalam membangun formasi spiritual. Hal ini juga berlaku untuk anak usia dini. Perbedaan yang cukup mencolok adalah ketika melihat interaksi anak usia dini dengan orang-orang di sekitar mereka. Anak usia dini membutuhkan kehadiran orang dewasa dengan lebih kompleks, sebab mereka memiliki berbagai kebutuhan dan kelemahan terkait dengan perkembangan fisik yang belum secara sempurna terbentuk. Kebutuhan dan tantangan dalam setiap masa memiliki perbedaan penekanan pada beberapa area, tetapi memiliki kesamaan terkait dengan tuntutan keikutsertaan orang dewasa bagi pendidikan anak usia dini, terkhusus dalam hal formasi spiritual.

\section{Anak Usia Dini dalam Konteks Biara}

Pertanyaan yang umum terkait dengan kehidupan dalam biara adalah siapa sajakah yang boleh masuk ke dalam biara untuk bergabung ke dalam komunitas spiritual ini? Pertanyaan ini dijawab dengan sangat baik oleh para pendahulu dalam biara. Di dalam catatan awal biara, terkhusus dalam The Rule of St. Benedict, pelayanan yang dilakukan di dalam biara diberikan kepada semua kalangan tanpa adanya pembedaan. Semua lapisan masyarakat, kaya atau miskin, muda atau tua, berpendidikan atau masyarakat awam, 
semua memiliki kesempatan yang sama untuk menerima didikan. ${ }^{30}$ Dengan demikian, semua orang memiliki kesempatan untuk dididik oleh sang "ayah" selaku representasi Kristus.

Menarik untuk diperhatikan bahwa komunitas dalam biara memutuskan untuk menerima anak-anak untuk menerima didikan yang sama dengan orang-orang dengan tingkat usia dan kedewasaan yang lebih tinggi. RB 59 menjelaskan bagaimana seorang anak yang masih di bawah pengawasan orang tua bisa masuk ke dalam biara dengan memenuhi beberapa syarat. ${ }^{31}$ Ketika mereka sudah masuk, maka yang bertanggungjawab atas mereka adalah para senior yang berada di biara. Untuk melihat siapa dan bagaimana seorang anak diperlakukan dengan "adil," RB 30 menjelaskan tentang hukuman yang diberikan kepada mereka, ${ }^{32}$

1. Every age and level of understanding should receive appropriate treatment. 2. Therefore, as often as boys and the young, or those who cannot understand the seriousness of the penalty of ex- communication, 3. are guilty of misdeeds, they should be subjected to severe fasts or checked with sharp strokes so that they may be healed.

Setiap orang memiliki hak dan kewajiban yang setara di dalam komunitas. Mereka memiliki kesempatan yang sama untuk belajar di bawah pengawasan yang lembut dan menerima penghukuman sebagai konsekuensi atas perbuatan mereka.

Di beberapa bagian RB, St. Benediktus menggunakan kata Latin, "infantum" atau yang akrab dipahami sebagai anak-anak usia dini. Kardong kemudian memberi penafsiran lebih lanjut mengenai boys and the young atau yang menurut Kardong adalah cbildren or youths. ${ }^{33}$ Catatan ini menunjukkan bahwa anak usia 15 tahun sudah bisa menerima hukuman dalam bentuk ekskomunikasi, mengingat bahwa mereka sudah memasuki masa remaja. Sedangkan yang disebut anak-anak adalah mereka yang berada di usia 12 tahun ke bawah. Lebih lanjut, menurut St. Benediktus, pemahaman mengenai anak-anak bukanlah semata-mata dari segi usia, melainkan kemampuan pemahaman (understanding) mereka dalam menanggapi pengajaran yang dilakukan di dalam biara. ${ }^{34}$ Oleh sebab itu, selama seorang anak sudah bisa menerima pengajaran, ia bisa menerima didikan, termasuk melalui instruksi, disiplin melalui aturan dan juga berarti penghukuman dari pihak berotoritas.

Melanjutkan pemaparan dari St. Benediktus mengenai keikutsertaan seorang anak, maka dapat dilihat bahwa kehadiran

${ }^{30}$ Fry, The Rule of St. Benedict in English, 81.

${ }^{31}$ Kardong, Benedict's Rule, 486.

${ }^{32}$ Fry, The Rule of St. Benedict in English, 54.

${ }^{33}$ Kardong, Benedict's Rule, 250.

${ }^{34}$ Ibid., 250. 
seorang anak untuk menerima didikan adalah hal yang tidak dapat ditunda ataupun diabaikan. Meski berada dalam usia yang relatif muda — dan berarti kurang berpengalaman—anak-anak sudah bisa mendapatkan pendidikan spiritual yang seimbang dan secara holistik di dalam dirinya. Aspek yang perlu dipertimbangkan adalah perbedaan perlakuan berdasarkan kemampuan setiap individu. Jadi, dapat dilihat bahwa pendidikan spiritual di masa biara dapat dilakukan kepada seorang anak bahkan dimulai sejak usia dini.

\section{Anak Usia Dini Masa Kontemporer: Kebutuhan dan Tantangan}

Sebuah penelitian yang dilakukan oleh Donald Ratcliff di awal milenium kedua menunjukkan data yang berbanding terbalik dengan pemaparan St. Benediktus. Keterbalikan yang dimaksud adalah adanya rentang waktu yang panjang di dalam sejarah yang menunjukkan kekosongan perhatian terkait dengan perhatian pada spiritualitas anak. Penelitian mengenai spiritualitas anak nampaknya kurang mendapatkan perhatian dari berbagai kalangan, terkhusus di Eropa, tempat penelitian Ratcliff dilakukan. Masa pertama kemunculan penelitian mengenai spiritualitas anak baru dimulai di tahun 1892 dengan gabungan penelitian antara spiritualitas dan juga psikologi anak. ${ }^{35}$ Setelah kemunculan penelitian yang pertama, maka ketertarikan untuk mempelajari spiritualitas anak mengalami perkembangan yang signifikan dengan berbagai penekanan yang berbeda dalam setiap periode waktu.

Ratcliff mencatat bahwa ada empat pembagian besar yang terjadi di dalam masa satu abad itu dalam meneliti spiritualitas anak, yaitu masa periode holistik (1892-1930), pengalaman (1930-1960), tahapan kognitif (1960-1990), dan perubahan lainnya (1990 sampai 2000-an). ${ }^{36}$ Satu tema yang sangat kuat muncul di masa tahapan kognitif adalah di dalam penelitian David Elkind, seorang psikolog, yang menyimpulkan bahwa anak-anak dengan usia yang muda (di bawah sebelas tahun) memiliki kesulitan untuk memahami konsepkonsep agamawi ketika menggunakan kemampuan akademik mereka. Akan tetapi, mereka bisa melihat konsep keagamaan (spiritual) berdasarkan referensi nyata yakni melalui kegiatan seharihari yang mereka lakukan. ${ }^{37}$ Di bagian terakhir dari penelitian ini, disebutkan bahwa hal yang paling penting terkait dengan spiritualitas seorang anak adalah kehadiran dan peranan orang tua yang bekerja sama dengan pihak-pihak terkait, seperti sekolah dan gereja, untuk membantu proses pertumbuhan spiritualitas anak. ${ }^{38}$

35 Ratcliff, “'The Spirit of Children Past:' A Century of Children's Spirituality Research," 218.

36 Ibid., 219.

37 Ibid., 224.

38 Ibid., 233. 
Kesamaan pihak-pihak terkait ini adalah melalui kehadiran sebagai pihak berotoritas yang memberi arahan relasional dan instruksional kepada anak.

Isu berikut yang juga perlu mendapat perhatian lebih adalah kurangnya perhatian pada anak, secara khusus pada anak usia dini. Secara umum, di dalam dunia pendidikan memberikan definisi "dini” yang dihitung dari usia 0-8 tahun. Anak-anak terlahir dengan kemampuan untuk menerima stimulasi spiritual yang berkembang ketika anak-anak usia dini ini menerima didikan paling awal dari relasi bersama orang tua. ${ }^{39} \mathrm{Hal}$ ini sesuai dengan dukungan teori Pestalozzi dan Montessori bahwa perkembangan spiritual seorang bayi dimulai dari sejak lahir melalui kasih yang diberikan oleh orang tua. ${ }^{40}$ Kebutuhan anak usia dini yang mendesak terkait dengan relasi dengan orang dewasa, baik dari orang tua, guru, orang dewasa lainnya, adalah kebutuhan untuk dikenal. ${ }^{41}$ Ketika kebutuhan ini terpenuhi, spiritualitas anak bisa berkembang dengan baik, sebaliknya interaksi yang minim akan menghambat perkembangan spiritualitas anak.

Salah satu bentuk interaksi yang keliru terkait dengan proses mendidik anak adalah dengan berfokus hanya kepada perkembangan pengetahuan saja. Ketidakseimbangan dengan aspek lainnya membuat anak usia dini ketika berada dalam tahapan perkembangan selanjutnya akhirnya memutuskan untuk menolak hal baik yang sudah ia ketahui di dalam pengetahuan mereka. David Hay menjelaskan bahwa, ${ }^{42}$

The problem is that anyone, child or adult, can learn off a list of such moral imperatives; perhaps even obtain an "A" grade for demonstrating proficient knowledge of them. At the end of the process, they may still have a boredom or detachment, even a cynicism about what they have learned.

Kondisi ini banyak dihadapi ketika di dalam perkembangannya, anak maupun orang dewasa tidak terdidik di dalam relasi yang kuat bersama orang dewasa yang mengajarkannya.

Penulis kemudian melihat kesinambungan pemahaman yang dicatat dalam The Rule of St. Benedict mengenai orang-orang yang seringkali disebut sebagai infant, anak-anak atau orang muda yang sedikit berpengalaman, tetapi memiliki kemampuan untuk menerima didikan. Secara usia, yang termasuk sebagai anak usia dini adalah mereka yang masih membutuhkan pengawasan dan bantuan secara langsung dari orang dewasa, terkhusus dalam

39 Deborah Schein, “Nature's Role in Children's Spiritual Development," Children, Youth and Environments, Vol. 24, No. 2 (2014): 83.

40 Ibid.

${ }^{41}$ Ibid., 84.

${ }^{42}$ Hay, "Why Should We Care about Children's Spirituality?” 13. 
formasi spiritual. Melengkapi pemahaman dari Abad Pertengahan, kondisi anak sepanjang zaman tetap menunjukkan keserupaan kebutuhan akan orang dewasa terkait dengan pemenuhan pertumbuhan spiritualitas mereka.

\section{Formasi Spiritual Anak Usia Dini: Peran Orang Dewasa}

Kebutuhan akan rasa aman adalah salah satu kebutuhan utama dari anak usia dini. ${ }^{43}$ Semakin aman anak, maka semakin baik bagi anak untuk bertumbuh dan mengembangkan spiritualitas mereka. Rasa aman diberikan oleh orang dewasa membuat anak menuntut sebuah relasi yang mendalam dari pihak orang dewasa. Orang dewasa yang terlibat aktif dalam perkembangan anak akan memberikan dampak positif bagi perkembangan anak.

Hasil penelitian Deborah Schein, seorang pakar anak usia dini, menjelaskan dampak yang diberikan oleh orang dewasa bagi perkembangan anak usia dini yang dimulai dari segi emosional dan yang kemudian memengaruhi aspek sosial bahkan empati. Salah satu partisipan dalam penelitian tersebut memberi testimoni sebagai berikut, ${ }^{44}$

Probably the most observed indicator of spiritual development is that of peer empathy. It's more than understanding. It's a shared experience: shared happiness, shared sorrow, and shared fun. You know, there is research that shows that babies have sympathetic cries, or when they hear another baby cry, they will cry, too. Two longitudinal studies (Wellman et al. 2008; Zayas et al. 2012) show that infants and very young children are capable of imitating and understanding intentional actions that become the bases for theories of mind that are believed to be the predecessor to moral judgment. Participants believed that it is possible that values and moral development may emerge from proper nurturing of spiritual development.

Peran orang dewasa di dalam perkembangan spiritual anak usia dini memegang peranan yang amat penting. Tanggung jawab orang tua, guru, dan berbagai pihak terkait perlu menyadari kebutuhan ini dengan baik agar formasi spiritual anak usia dini bisa tercapai secara maksimal.

\section{Kehadiran Otoritas: Wujud Ultima Kasih bagi Anak Usia Dini}

St. Benediktus dari masa awal Abad Pertengahan telah secara implisit menunjukkan mengenai signifikansi proses

${ }^{43}$ Schein, "Nature's Role in Children's Spiritual Development," 84.

44 Ibid., 86. 
pertumbuhan spiritual di dalam diri seorang anak, meskipun dalam lingkup usia masih sangat muda. Pemahaman yang serupa juga terlihat dari penelitian Ratcliff sehubungan dengan kebutuhan yang muncul terkait dengan spiritualitas anak, ${ }^{45}$

There is great need for dialogue between those interested in spiritual formation and advocates of children's spiritual development. Theology and children's spiritual experience should be natural partners, and advocates of spiritual formation could be natural link between these. This seems particularly likely if child development is conceptualized in a more holistic manner, with spirituality not merely being added to other areas of cognitive and social development, but rather seen as inseparable from these and other aspects of development. Religion and spirituality should relate to every area of the child's life.

Terkait dengan kondisi ini, maka pihak-pihak yang secara langsung terkait dengan pertumbuhan spiritual anak harus kembali memperhatikan peran dan fungsi dalam hidup anak. Penumbuhan hidup spiritual secara dini akan memengaruhi hidup anak secara holistik.

Hidup spiritualitas anak adalah hal yang menarik untuk diteliti karena terlihat sangat menantang. Ketegangan yang terlihat adalah kesadaran bahwa hal ini amat penting untuk diperhatikan, namun juga sangat sulit untuk dilakukan. Anak-anak belum cukup mampu untuk mengupayakan hidup spiritual mereka, oleh sebab itu mereka selalu perlu dibantu oleh pihak luar, terkhusus pihak yang ada di sekitar mereka. Beberapa pihak yang berotoritas, seperti komunitas dalam keluarga, sekolah, gereja, perlu memastikan bahwa peran otoritatif yang melekat sudah dilakukan dengan baik.

Warisan budaya dari awal Abad Pertengahan yang masih bertahan sampai sekarang, menjadi acuan yang tepat untuk merumuskan kembali peran pihak otoritatif. Model peran yang dimiliki oleh kepala biara adalah salah satu contoh peranan otoritatif yang tepat untuk diterapkan untuk mendidik anak dalam hidup spiritual secara holistik. Kepala biara menunjukkan bahwa peran otoritatif yang penuh dengan kuasa, yang cenderung mutlak, bisa digunakan untuk mendidik seseorang untuk memiliki kehidupan spiritual yang sejati. Penekanan kepada peran sebagai ayah yang mendidik dalam kerangka representasi Kristus bisa dilakukan dengan menerapkan hukuman, sebagai bagian dalam

45 Ratcliff, “"The Spirit of Children Past': A Century of Children's Spirituality Research,” 233. 

Implikasinya dalam Pendidikan Anak Usia Dini

proses pendisiplinan. ${ }^{46}$ Akan tetapi, kepala biara tetap menunjukkan perhatian dan kasih. Terkait dengan peran sebagai kepala biara, pihak berotoritas perlu selalu memiliki kepekaan untuk menunjukkan kelemahlembutan pada orang-orang yang ia layani seperti yang tertulis di RB $27,{ }^{47}$

4. ... let love for him be reaffirmed and let everyone pray for him. 5. The abbot must indeed exercise very great care and hasten with all keenness and energy to prevent any of the sheep in his care from being lost. 6. He should understand that he has undertaken to care for the weak ...

Pemberian konsekuensi harus dilakukan dengan tujuan untuk mendidik jiwa agar berbalik kepada hidup dalam aturan untuk hidup yang benar. Keseimbangan peran yang dimiliki oleh pihak berotoritas juga nampak dalam model yang lebih lembut sebagaimana seorang ibu yang telah mengandung dan mengasuh anaknya. Menggunakan kelemahlembutan tidaklah menunjukkan sisi permisif, melainkan untuk menolong anak memiliki pemahaman akan Allah dengan lebih mendalam. Pemberian afeksi kepada anak usia dini akan menolong anak untuk mengembangkan kualitas personal yang baik dalam proses tumbuh kembang mereka, termasuk cara berelasi dengan Allah dan sesama. Di dalam melakukan tugas peran sebagai orang tua yang mendidik, pihak otoritatif juga harus selalu berusaha menjaga keseimbangan peran untuk mengatur dan mengurus hal-hal bersifat administratif di dalam pertumbuhan spiritual anak yang holistik. Dengan menyediakan hal-hal yang dibutuhkan dalam perkembangan anak, maka anak usia dini juga bisa belajar untuk meniru dan meneladani cara untuk melakukan tanggung jawab di dalam lingkungan pertumbuhannya. Menjaga ketegangan ini jelas bukanlah hal yang mudah, oleh sebab itu diperlukan sebuah kesadaran penuh bahwa hal yang dilakukan adalah sebagai representasi Kristus di dalam kehidupan anak. Dengan menjalankan hal ini, diharapkan bahwa kehidupan spiritual anak usia dini bisa tercapai dalam kerangka otoritas yang mencerminkan kasih Kristus.

\section{Kesimpulan}

Pihak otoritatif-yang dideskripsikan melalui kehadiran kepala biara-menunjukkan bahwa peranan dengan kuasa mutlak tetap berdampak bagi kehidupan spiritual anak. Otoritatif tidak berarti otoriter, terkait dengan proses pendisiplinan, pihak

${ }^{46}$ Meskipun disebutkan peran sebagai ayah, hal ini tidak dibatasi oleh gender, melainkan merujuk kepada peran. Di dalam tradisi biara, kepala biara juga dipimpin oleh wanita yang disebut sebagai abbess.

${ }^{47}$ Kardong, Benedict's Rule, 240. 
otoritatif perlu menyadari bahwa hal yang dilakukan dibangun di dalam kerangka relasi yang penuh dengan kasih. Ketegangan peran antara kuat dan lembut, jauh dan dekat harus selalu dijaga agar anak usia dini dapat memiliki makna yang utuh mengenai gambaran Allah di dalam hidup mereka secara holistik. Makna kehadiran utama seorang pemimpin spiritual adalah hadir sebagai representasi Kristus untuk menunjukkan kasih yang benar dan otentik. Kehadiran pihak otoritatif harus ditandai dengan peranan yang utuh dan seimbang.

Usulan dari penelitian ini adalah agar pihak otoritatif dapat melaksanakan peran yang utuh untuk menolong anak usia dini memiliki pertumbuhan spiritual yang baik. Memberi perhatian kepada pertumbuhan spiritual bagi anak usia dini tidak dibatasi oleh usia ataupun pada perkembangan secara parsial, sebagai contoh kognitif saja, melainkan secara holistik. Setiap anak membutuhkan kekhususan dalam menerima pendidikan spiritual. Oleh sebab itu, sedari dini, anak membutuhkan figur otoritatif sebagai representasi Kristus yang hadir dengan penuh kasih untuk menolong mereka mencapai hidup spiritual yang utuh. Jadi, pemimpin/orang dewasa yang mendampingi anak usia dini perlu hadir sebagai ayah, ibu, dan "Maria dan Marta" yang bertujuan menghasilkan perubahan hidup bagi setiap anak yang dilayani. Melalui kesadaran ini, pihak otoritatif dapat membangun formasi spiritual yang transformatif dalam peran sebagai representasi Kristus.

\section{Tentang Penulis}

Meiliana Evita Benes adalah lulusan program studi Magister Divinitas Sekolah Tinggi Teologi Amanat Agung, Jakarta, tahun 2021. Ia saat ini sedang melayani di Gereja Kebangunan Kalam Allah Jemaat Panakkukang, Makassar.

\section{Daftar Pustaka}

Bradley, James E., Richard A. Muller, Robert Bideleux, and Ian Jeffries. Church History: An Introduction to Research, Reference Works, and Methods. $2^{\text {nd }}$ ed. Grand Rapids, MI: Eerdmans, 1995.

Bynum, Caroline Walker. "Jesus as Mother and Abbot as Mother: Some Themes in Twelfth-Century Cistercian Writing." Medieval Religion: New Approaches, Vol. 15, No. 1975 (2004): 1843. https://doi.org/10.1525/9780520907539-007.

Derkse, Wil. The Rule of Benedict for Beginners: Spirituality for Daily Life. Collegeville, MN: The Liturgical Press, 2003.

Escobar, Melody. "Horses of Hospitality: A Transformative Pathway to the Christian Praxis of Love." Spiritus A Journal of Christian Spirituality, Vol. 19, No. 2 (2019): 217-231. 10.1353/scs.2019.0028. 
265 Peranan Abbot Sebagai Representasi Kristus dan Implikasinya dalam Pendidikan Anak Usia Dini

Fry, Timothy. The Rule of St. Benedict in English. Collegeville, MN: The Liturgical Press, 1982.

Hay, David. "Why Should We Care about Children's Spirituality?" Pastoral Care in Education, Vol. 16, No. 1 (1998): 11-16. https://doi.org/10.1111/1468-0122.00078.

Heale, Martin. The Abbots and Priors of Late Medieval and Reformation England. Oxford: Oxford University, 2016.

Holder, Arthur. The Blackwell Companion to Christian Spirituality. Malden, MA: Blackwell, 2005.

Kardong, Terrence G. Benedict's Rule: A Translation and Commentary. Collegeville, MN: The Liturgical Press, 1996.

Maas, Robin. Spiritual Traditions for the Contemporary Church. Nashville, TN: Abingdon, 1990.

Miller, Craig. "Schools for the Lord's Service: The Rule of St. Benedict for Christian Camping." Christian Education Journal: Research on Educational Ministry, Vol. 11, No. 2 (2014): 300-317. https://doi.org/10.1177/073989131401100206.

Ratcliff, Donald. “The Spirit of Children Past': A Century of Children's Spirituality Research." Christian Education Journal: Research on Educational Ministry, Vol. 4, No. 2 (2007): 218-237. https://doi.org/10.1177/073989130700400203.

Schein, Deborah. "Nature's Role in Children's Spiritual Development." Children, Youth and Environments, Vol. 24, No. 2 (2014): 78-101.

Tupikowski, Jerzy. "Anthropology of the Evangelical Counsels in the School of St. Benedict of Nursia." The Person and the Challenges, Vol. 8, No. 2 (2018): 205-219.

Vogue, Adalbert De. Reading Saint Benedict: Reflections on the Rule. Collegeville, MN: The Liturgical Press, 1994.

White, Carolinne. The Rule of Benedict. London: Penguin Classics, 2008. 